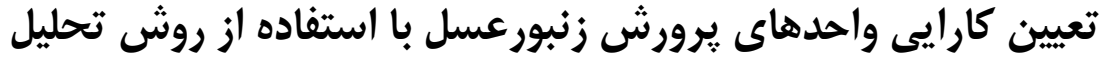

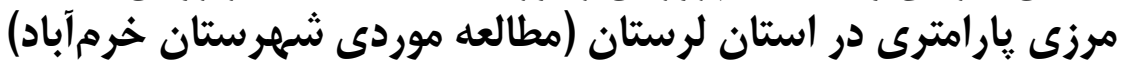

\author{
بهروز يار احمدى'، محسن محمدى ساعى '، كريم قربانى 'و رضا بيهلوانىع
}

\author{
1- استاديار، عضو هيات علمى بخش تحقيقات علوم دامى مركز آموزش و تحقيقات كشاورزى و منابع طبيعى لرستان،

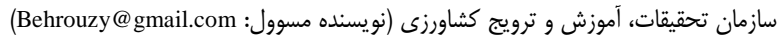 \\ r و ץ- دانش آموخته دكترى و مربى يزوهشى علوم دامى، بخش تحقيقات آنقات علوم دامى مركز آموزش و و تحقيقات كشاورزى و منابع طبيعى لرستان،

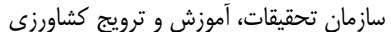

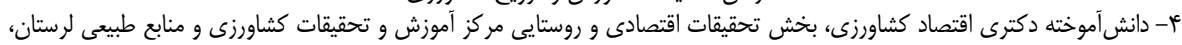

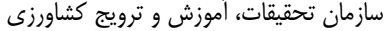

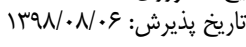

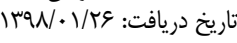

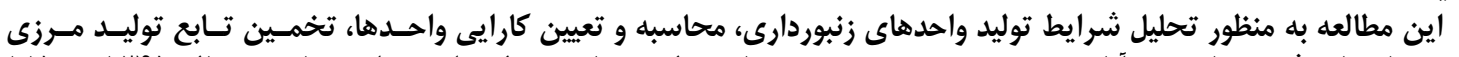

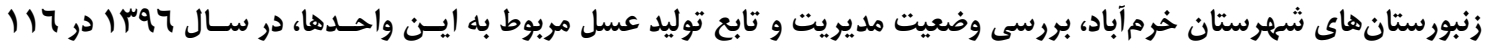

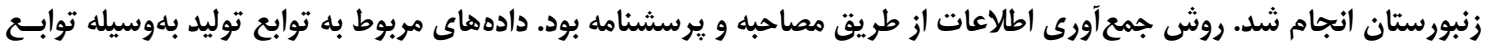

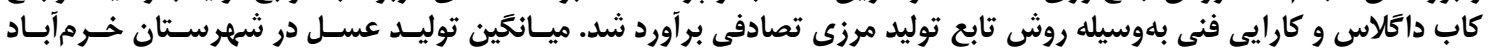

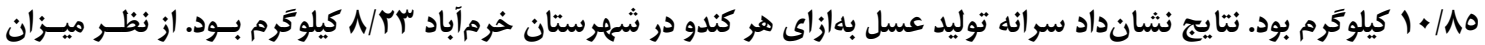

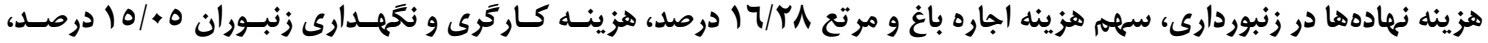

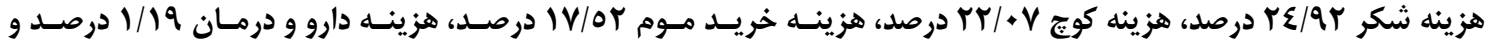

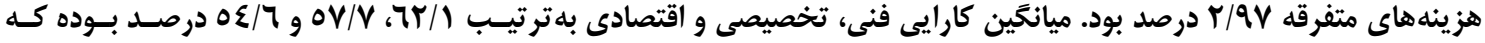

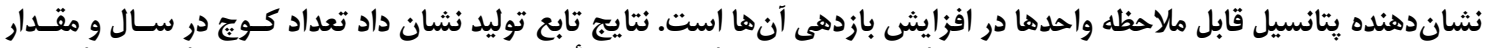

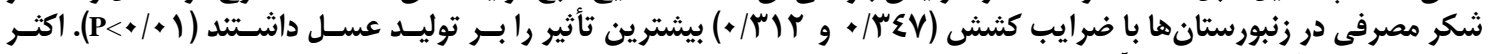

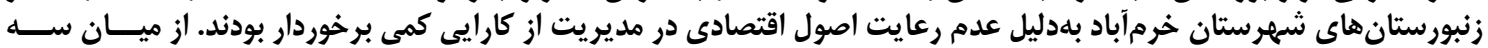

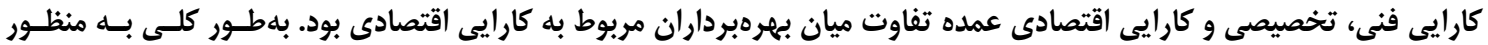

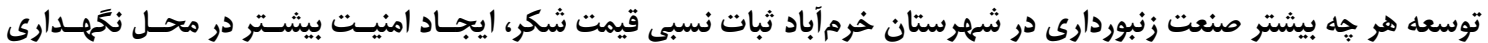

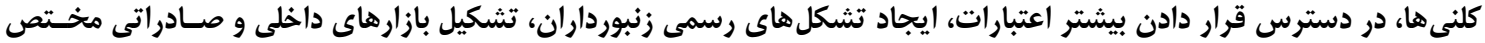
توليدات زنبورعسل، بيمه كردن توليدات ضرور دارت دارد.

وازههاى كليدى: تابع توليد مرزى تصادفى، توابع كاب داكَلاس، زنبور عسل، شهرستان خرمآباد، كارايى

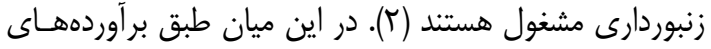

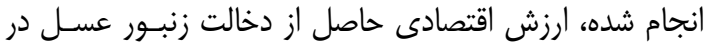

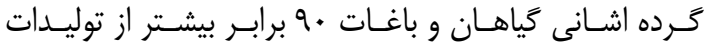

$$
\text { مستقيم آن است (أ) (l). }
$$

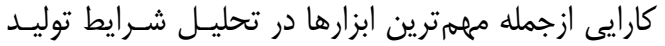

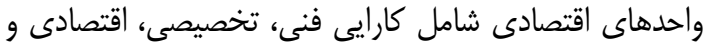

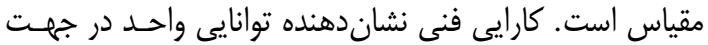

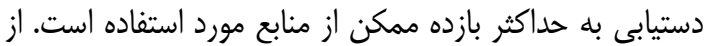

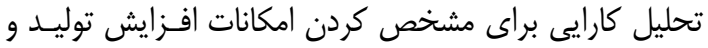

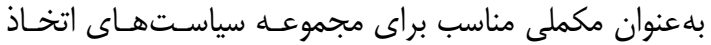

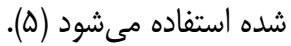

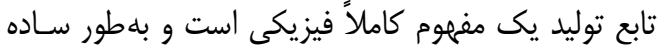

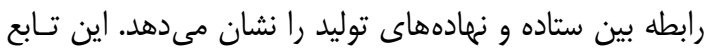

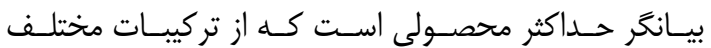

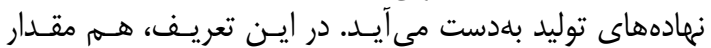

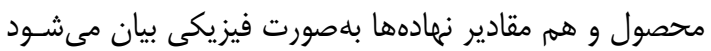

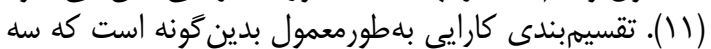

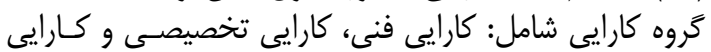

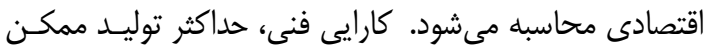
است كه بتوان از مقدار مشخصى عوامل توليدى بهاددست آورد.

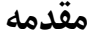

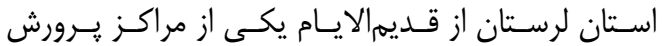

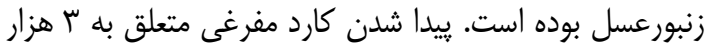

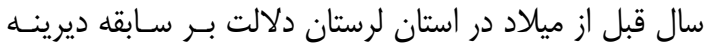

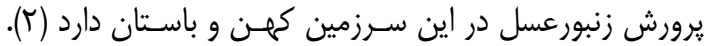

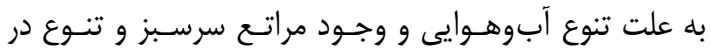

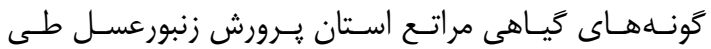

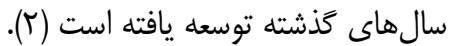

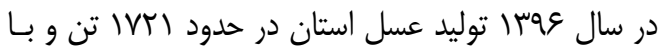

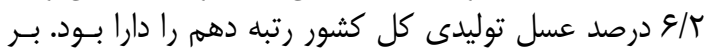

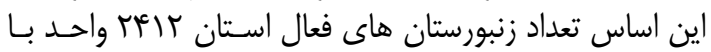

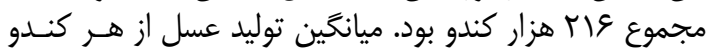

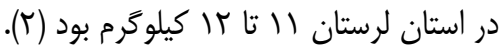

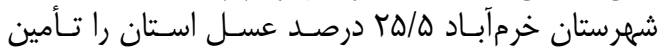

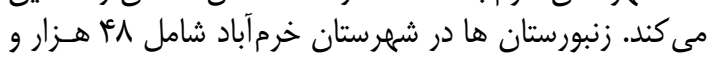

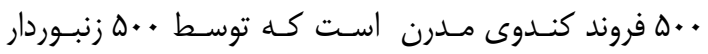

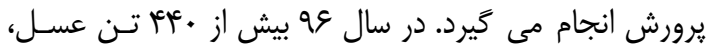

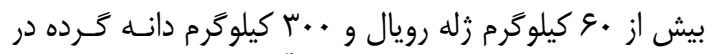

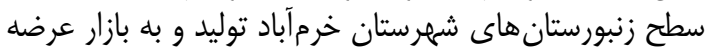

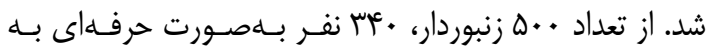




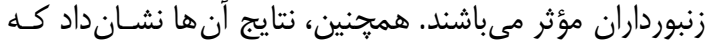

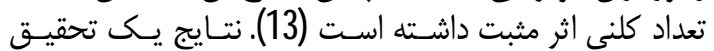

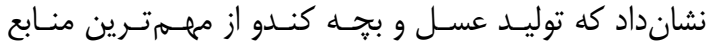

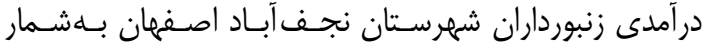

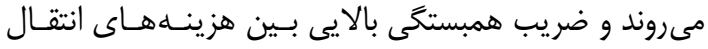

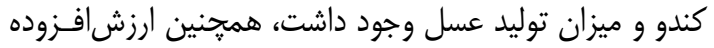

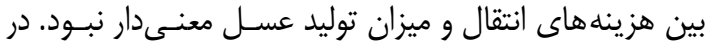

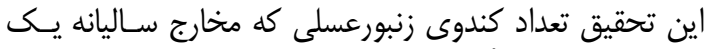

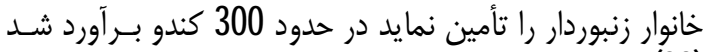

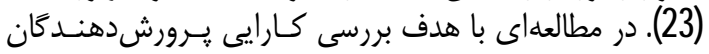

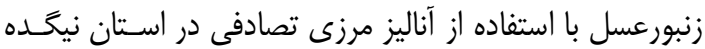

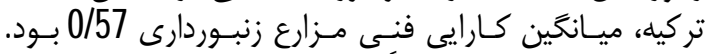

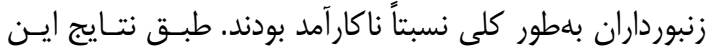

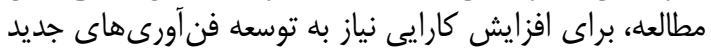

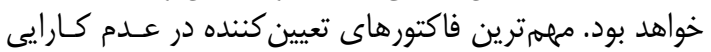

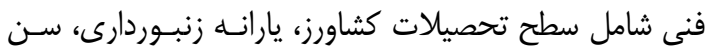

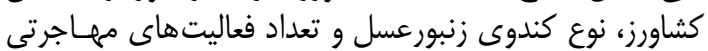

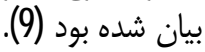

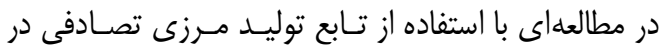

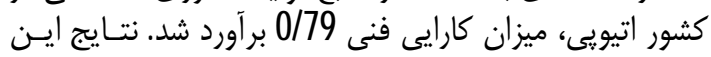

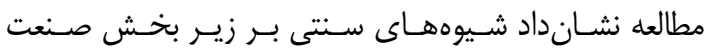

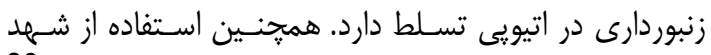

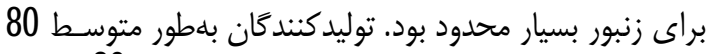

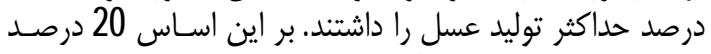

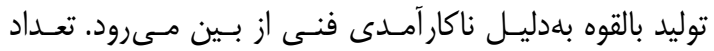

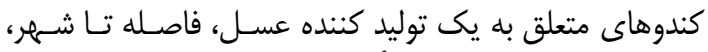

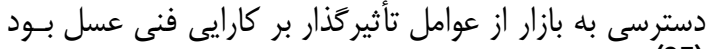

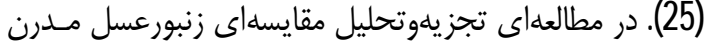

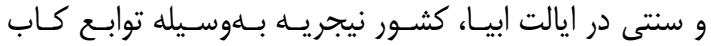

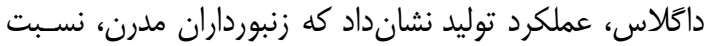

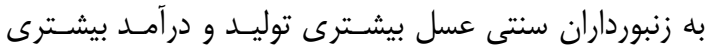

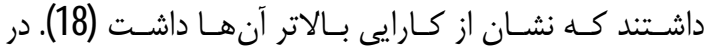

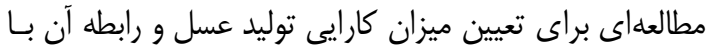

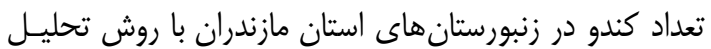

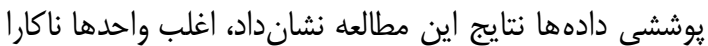

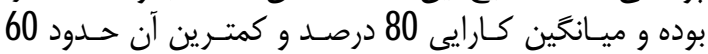

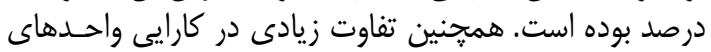

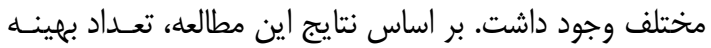

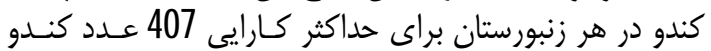

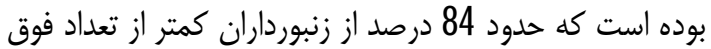

كندو داشتند (15).

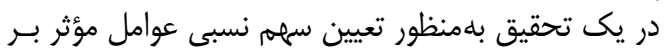

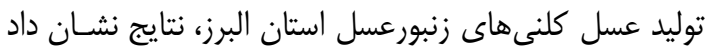

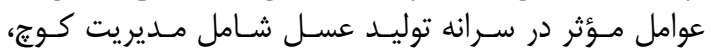

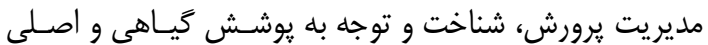

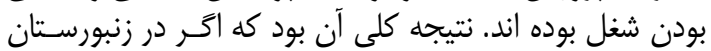

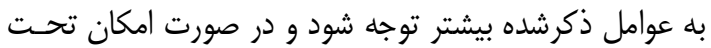

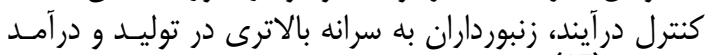

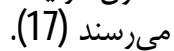

كارايى تخصيصى نيز به كارگيرى تركيبى از عوامل توليد است

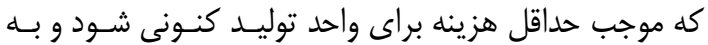

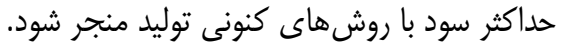

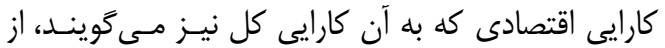

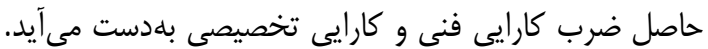

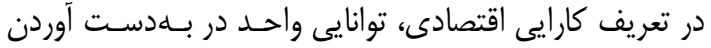

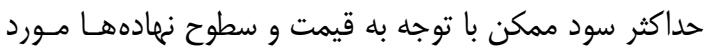
توجه است (2829،ها ه).

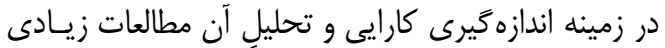

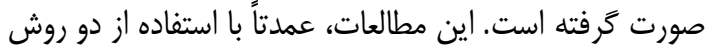

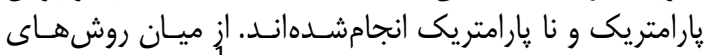

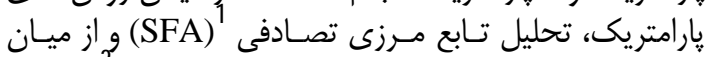

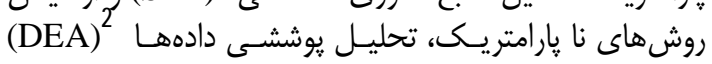

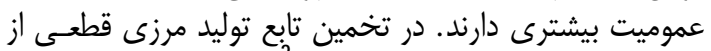

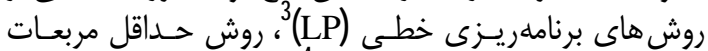

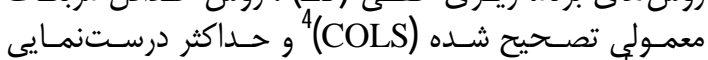
(ML)

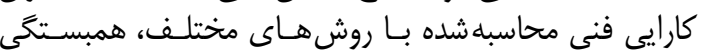

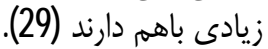

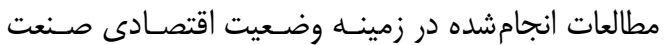

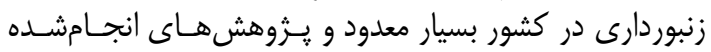

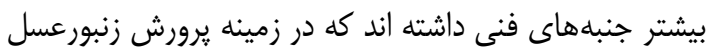

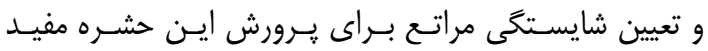

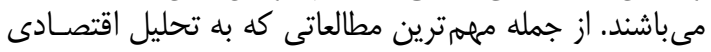

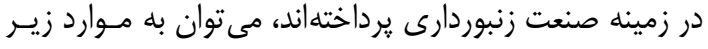

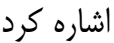

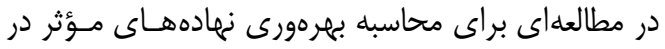

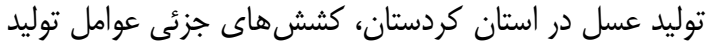

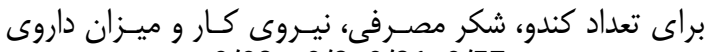

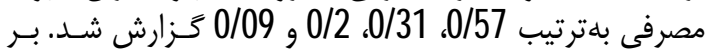

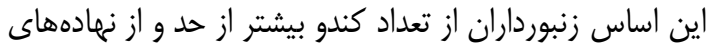

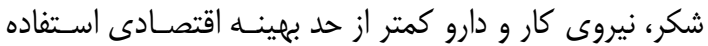

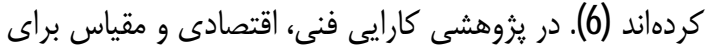

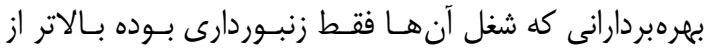

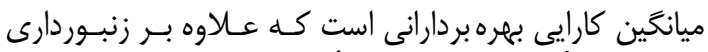

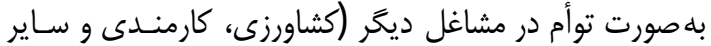
مشاغل) فعاليت كردند (26). (20)

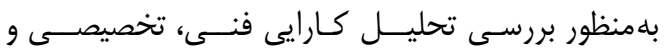

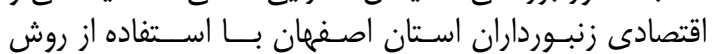

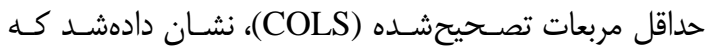

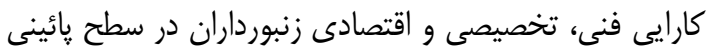

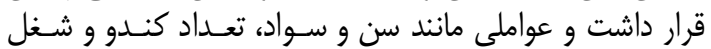
اصلى نيز بر كارايى تأثير داشت (10).

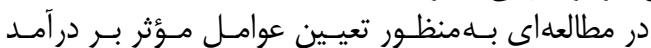
زنبورداران شهر ستان هاى اصفهان، خمينى شهر و نجف آبـاد بـانـا

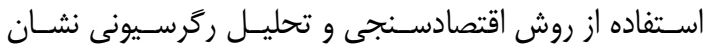

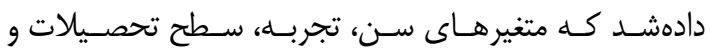

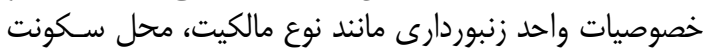

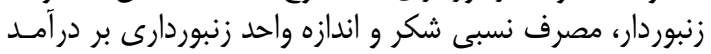




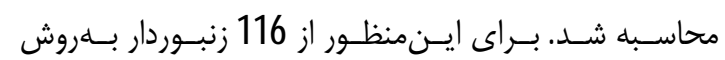

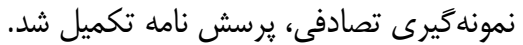

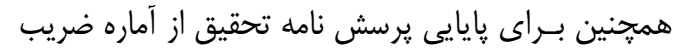

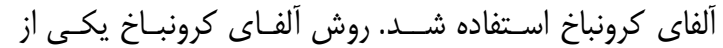

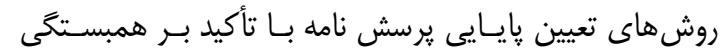

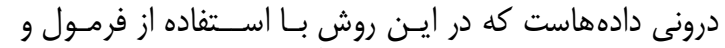

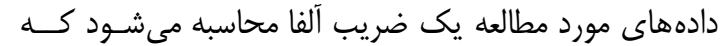

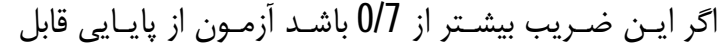

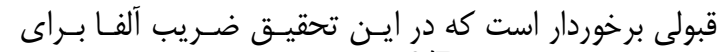

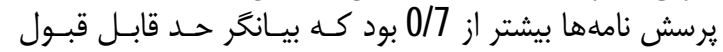

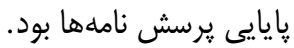

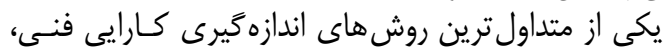

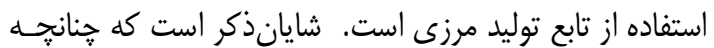

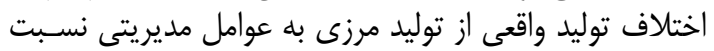

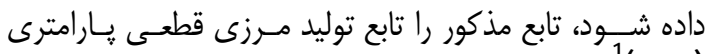

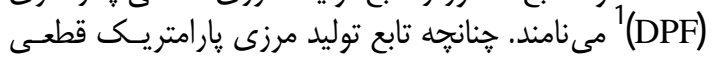

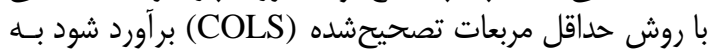

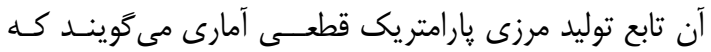

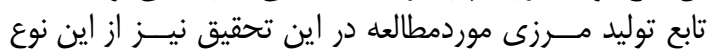

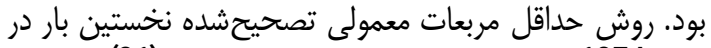

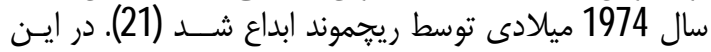

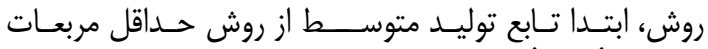

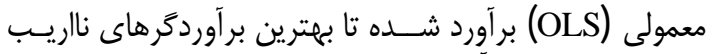

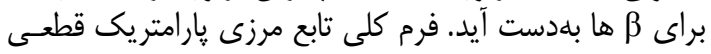
بلمورت زير مىباشد:

$Y_{i}=f\left(X_{k i}, \beta\right) \exp \left(-u_{i}\right)$

رابطه (1)

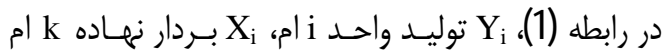

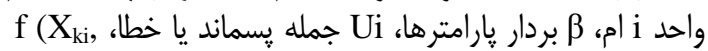

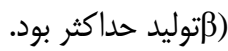

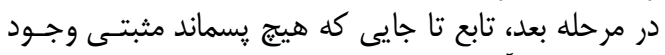

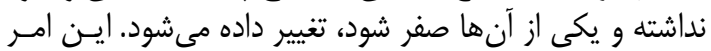

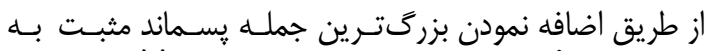

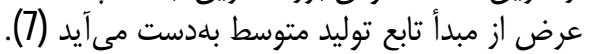
اكر تابع توليد كاب - داكلاس بلهصورت ذيل باشد باشد:

$\operatorname{LnQ}=A \sum_{\mathrm{i}=1}^{\mathrm{m}} \mathrm{a}_{\mathrm{i}} \ln \mathrm{X}_{\mathrm{i}}$

(2) (2)

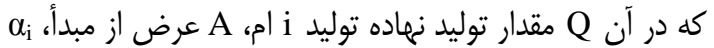
كشش توليد، X نهاده

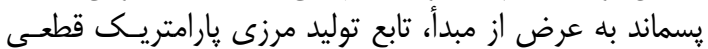
آمارى بهصورت زير بهدست مى آيد:

$\operatorname{LnQ}_{\mathrm{f}}=\dot{\mathrm{A}}+\sum_{\mathrm{i}=1}^{\mathrm{m}} \mathrm{a}_{\mathrm{i}} \ln \mathrm{X}_{\mathrm{i}}$ رابطه (3)

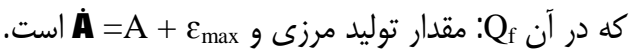

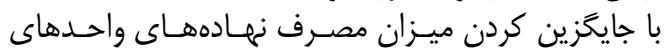

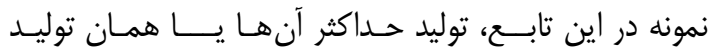

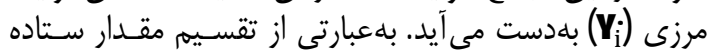

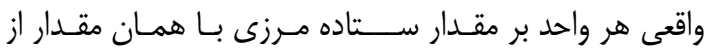
نهاده هاى مصرفى، كارايى فنى واحسـ محاسـبه مـى شـود از
بلهنظـور بررسـى نيازهـاى آموزشـى زنبـورداران اسـتان

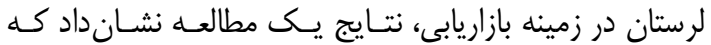

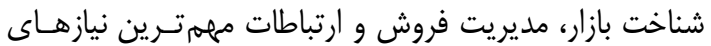

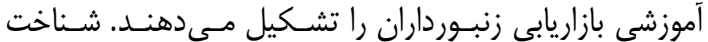

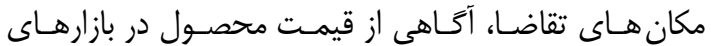

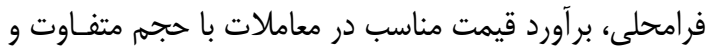

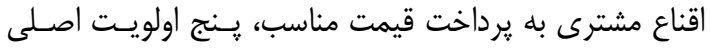

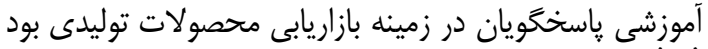

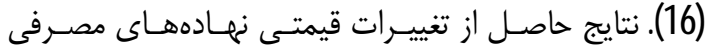

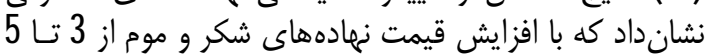

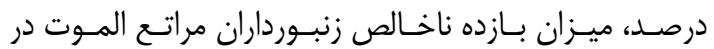

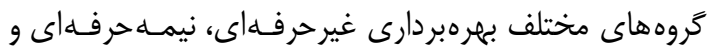

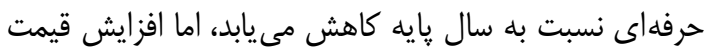

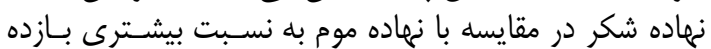

ناخالص زنبورداران را كاهش مى دهائد (19).

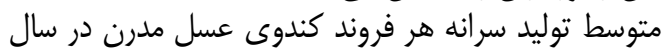

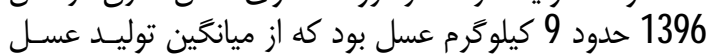

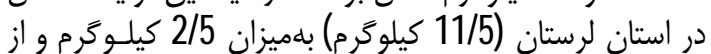

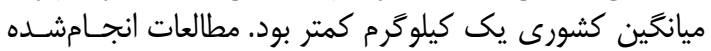

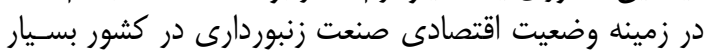

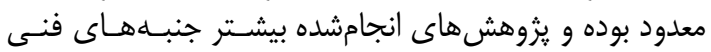

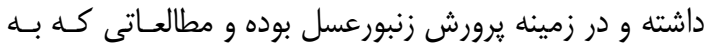

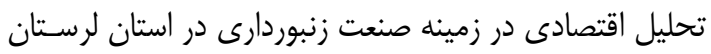

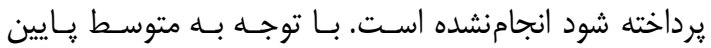

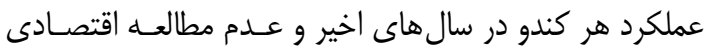

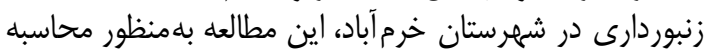

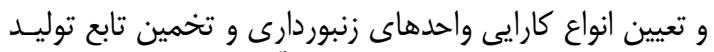

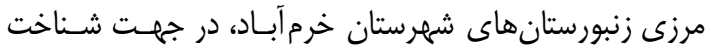

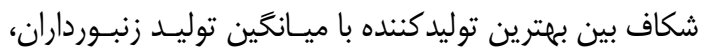
ضرايب يارامترهاى توليد برآورد شد.

\section{مواد و روشها}

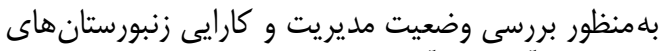

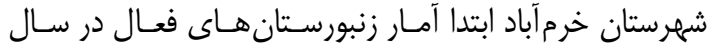

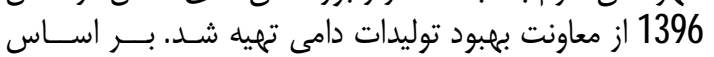

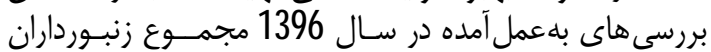

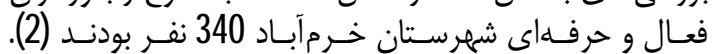

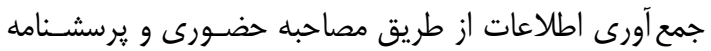

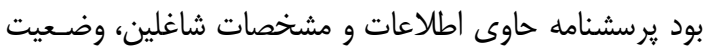

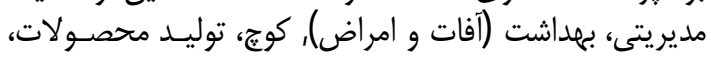

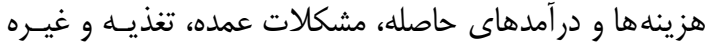

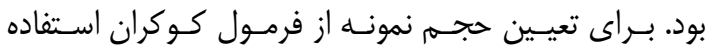

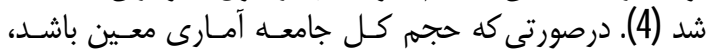
$\mathrm{n}=\left[\mathrm{N}(\mathrm{t} . \mathrm{s})^{2}\right] /\left[\mathrm{N} \cdot \mathrm{d}^{2}+(\mathrm{t} . \mathrm{s})^{2}\right]$ اين فرمول بلهورت زير است.

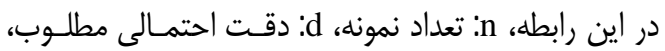

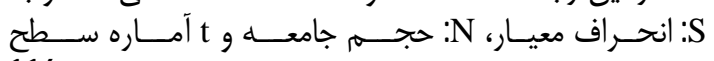
معنى دارى است. تعداد نمونه بر اسـاس فرمـول كـوكران 
با جايخزين كردن ميزان مصرف نهادههاى كمى در ايـن

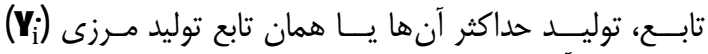

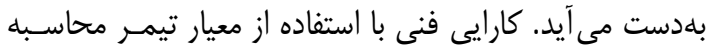

ش شاره زنبورستان Yi

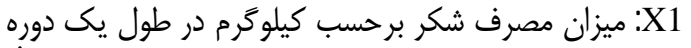

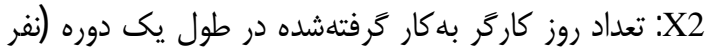

خدمات واكسن، داميزشك، بهداشت و درمان (تعداد X3 بازديد)

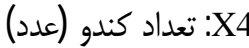

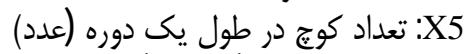

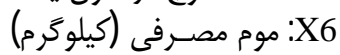

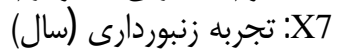

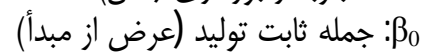

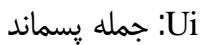

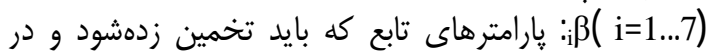

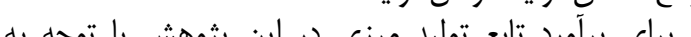

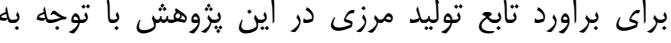

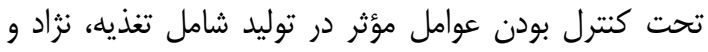

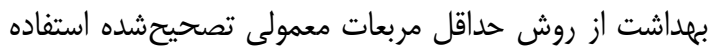

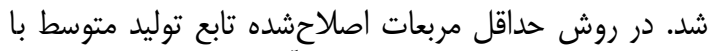

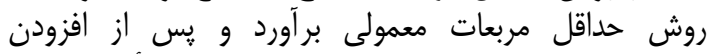

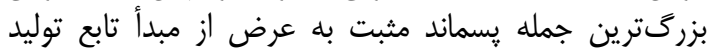

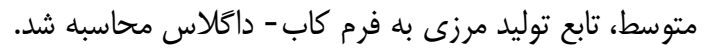

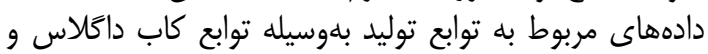

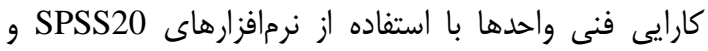
Frontier4

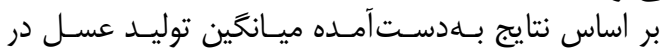

\section{نتايج و بحث}

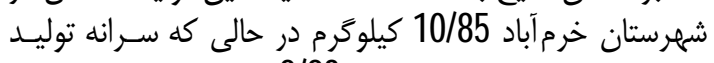

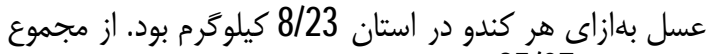

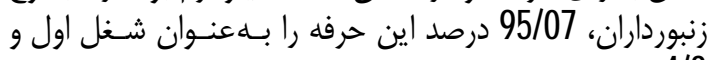

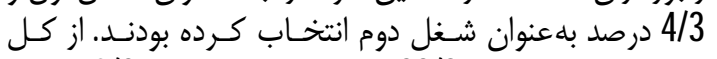

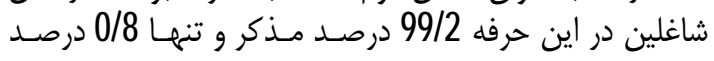

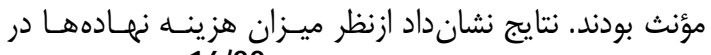

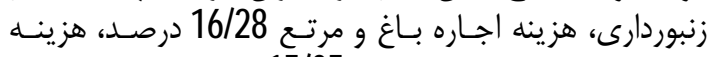

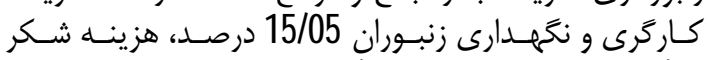

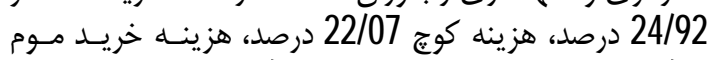

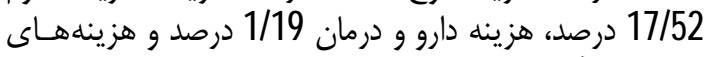

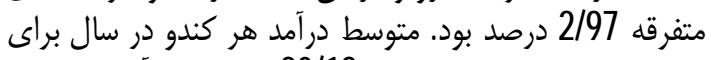

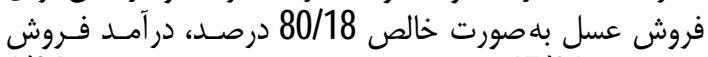

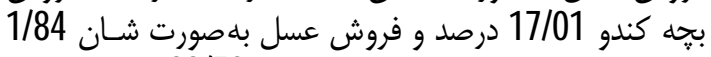

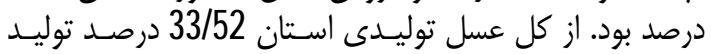
عسل در داخل استان مصرفش توليده و66/48 درصد به به خـارج از

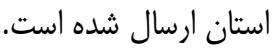

معيار تيمر براى اندازهخيرى كارايى فنى بلصورت زير استفاده شد (27). $\mathrm{TE}_{\mathrm{i}}=\frac{\mathrm{Y}_{\mathrm{i}}}{\mathrm{Y}_{\mathrm{i}}}$

رابطــــ (4) كه در آن TE

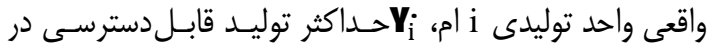

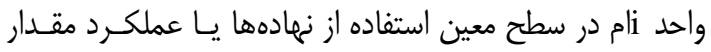

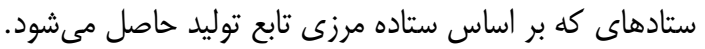

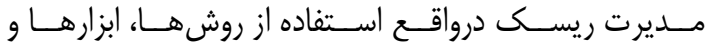

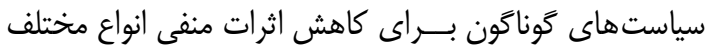

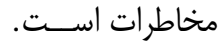

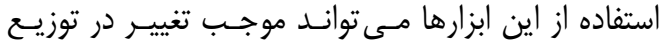

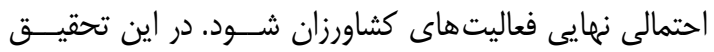

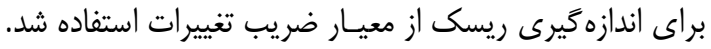

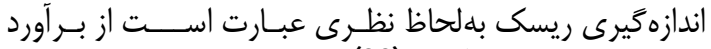

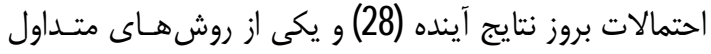

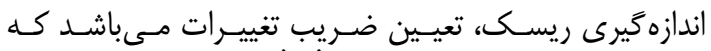
بdصورت زير محاسبه شده است تعاست (22).

$\mathrm{CV}=\frac{\mathrm{SD}}{\mathrm{M}}$

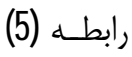

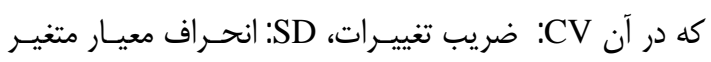

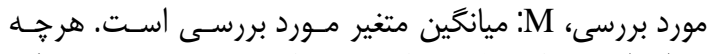

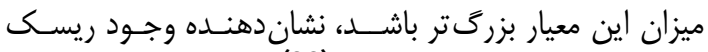
بالاتر براى متغير مورد نظر است (22).

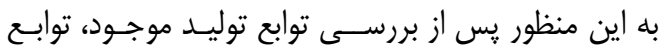

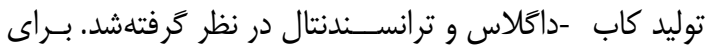

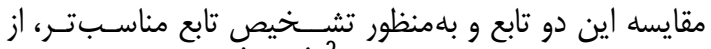

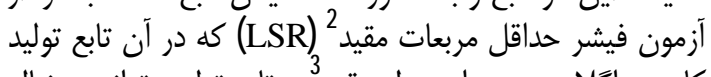

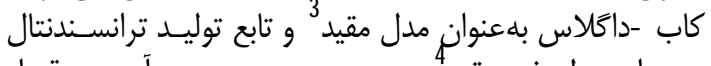

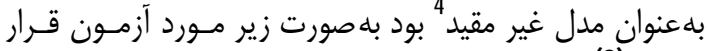

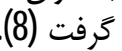
$\mathrm{F}=\frac{\left(\mathrm{R}_{\mathrm{UR}}^{2}-\mathrm{R}_{\mathrm{R}}^{2} / \mathrm{m}\right)}{\left(1-\mathrm{R}_{\mathrm{UR}}^{2}\right)(\mathrm{N}-\mathrm{K})} \quad$ (6)

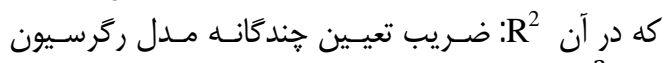

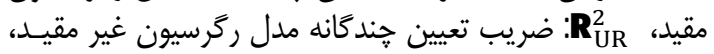

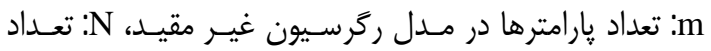

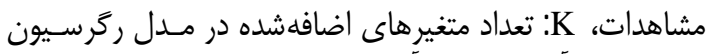

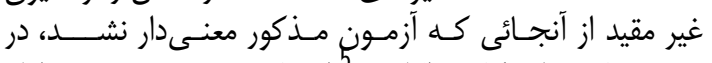

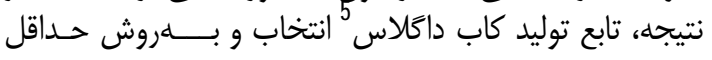

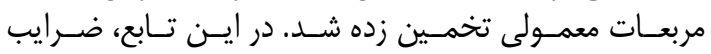

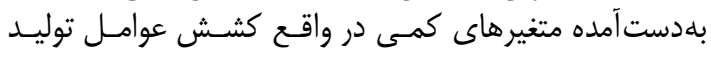

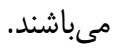

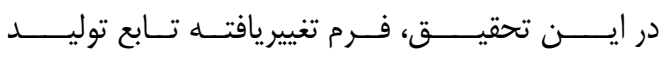

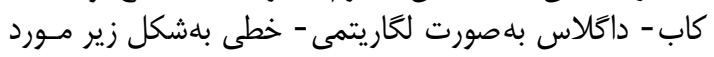

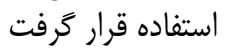
رابطه (7)

$\operatorname{LnY}_{\mathrm{i}}=\beta_{0}+\beta_{1} \ln \mathrm{X}_{1 \mathrm{i}}+\beta_{2} \ln \mathrm{X}_{2 \mathrm{i}}+\beta_{2} \ln \mathrm{X}_{3 \mathrm{i}}+\beta_{4} \ln \mathrm{X}_{4 \mathrm{i}}+\beta$ ${ }_{5} \ln X_{5 i}+\beta_{6} \ln X_{6 i}+\beta_{7} \ln X_{7 i} U_{i}$ 


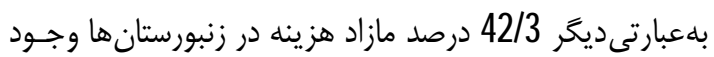

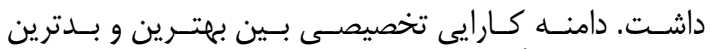

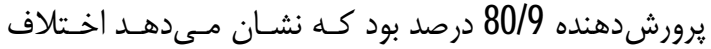

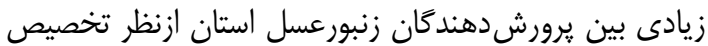

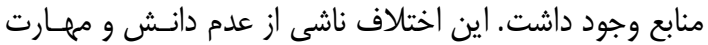

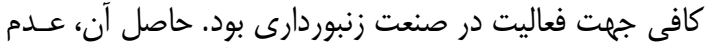

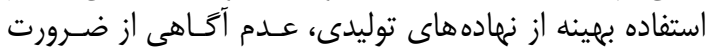

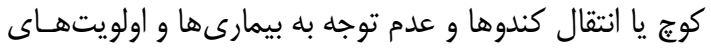

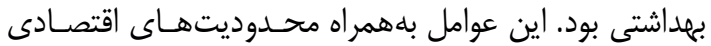

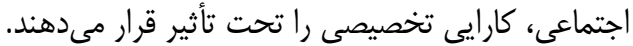

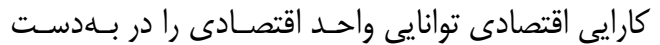

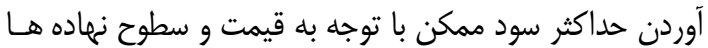

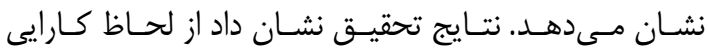

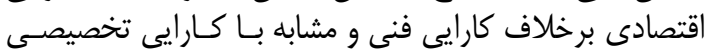

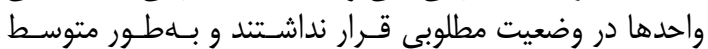

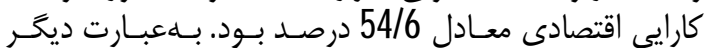

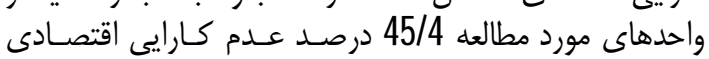

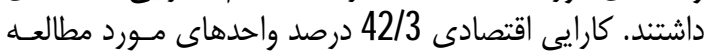

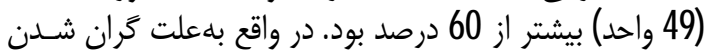

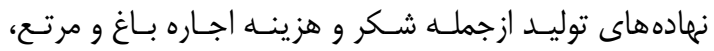

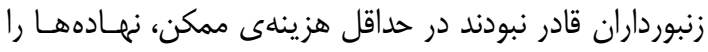

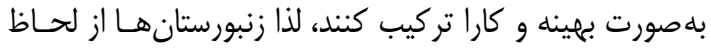
اقتصادى كارا نبودند.

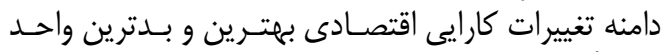

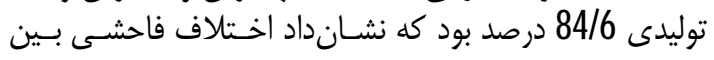

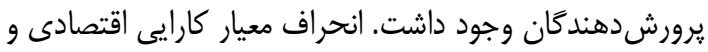

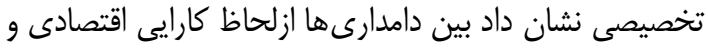
تخصيصى تنوع زيادى وجود داشت.

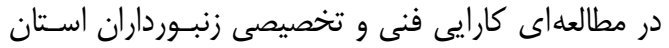

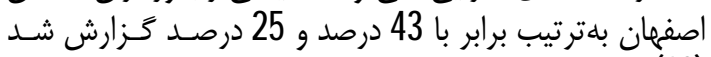

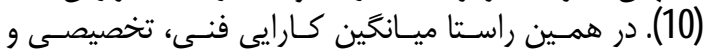

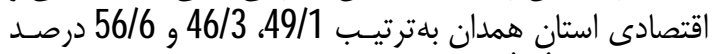

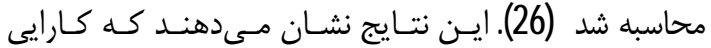

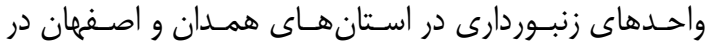

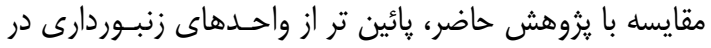
خرم اباد است.

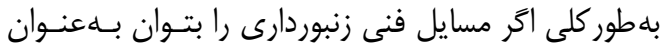

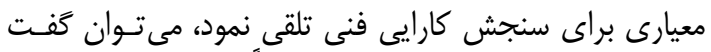

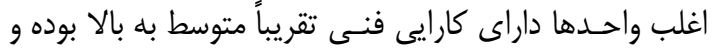

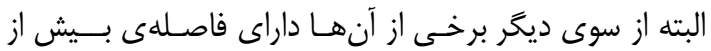

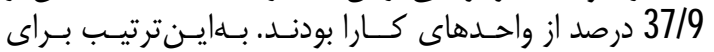

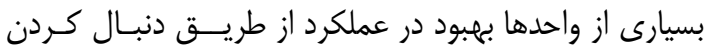

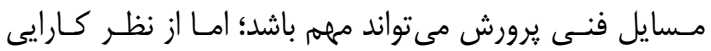

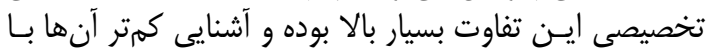

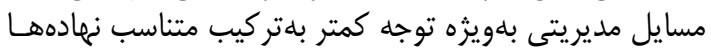

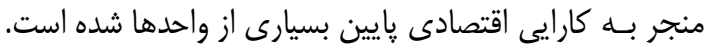

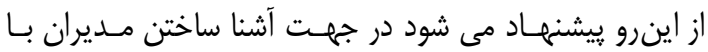

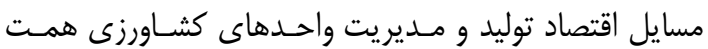

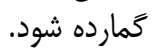

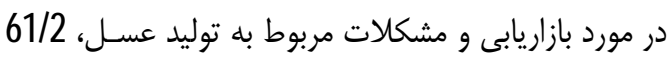

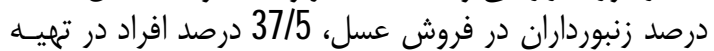

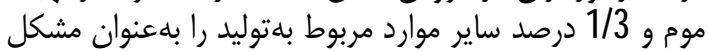

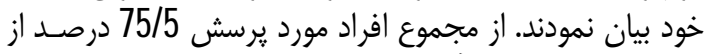

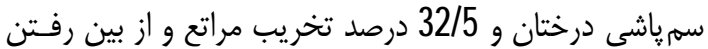

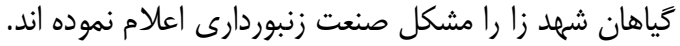

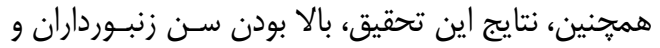

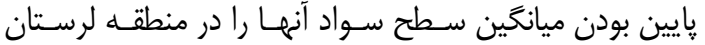

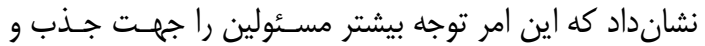

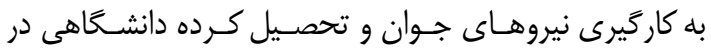

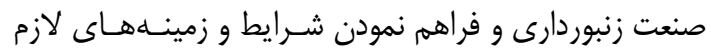

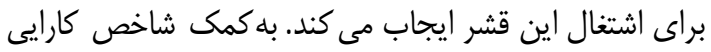

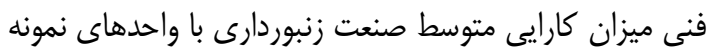

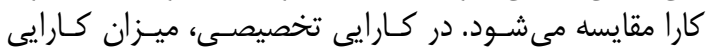

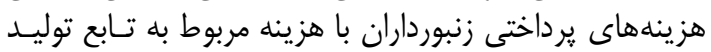

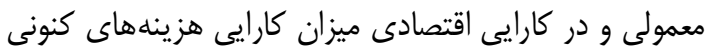

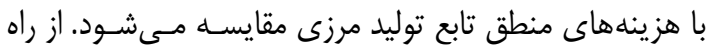

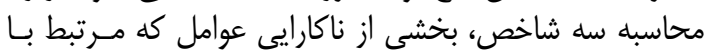

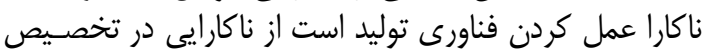

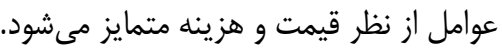

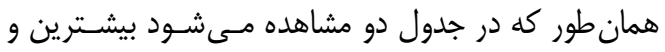

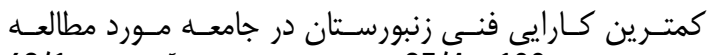

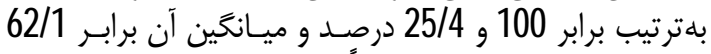

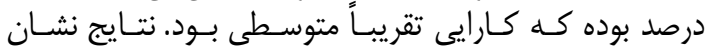

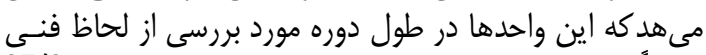

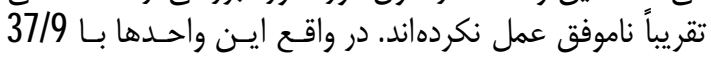

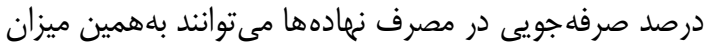
توليد عسل دست يابند.

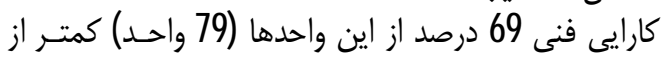

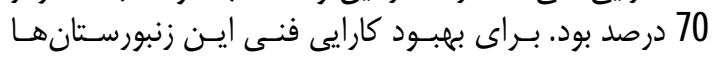

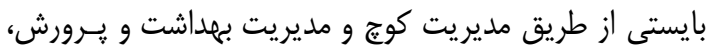

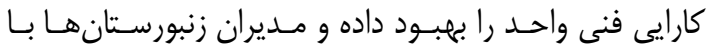

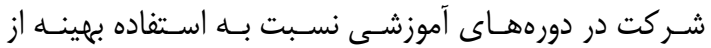

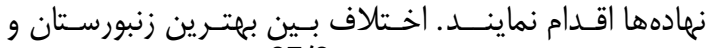

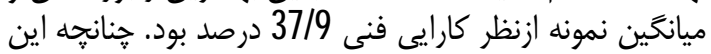

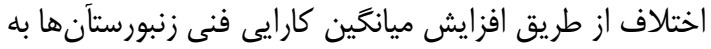

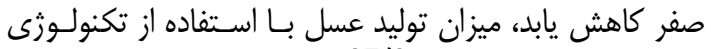
موجود و عوامل مشخص، 37/9 درابن مرصد قابل افزايش است.

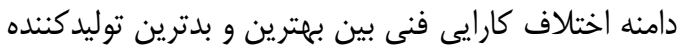

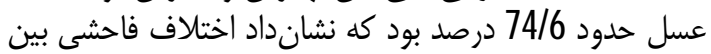

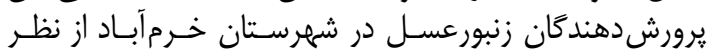
مديريتى وجود دارد.

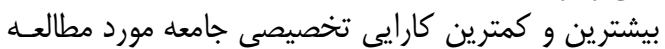

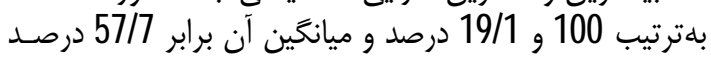

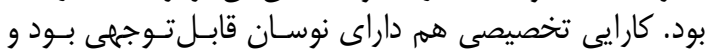

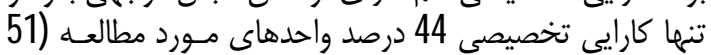

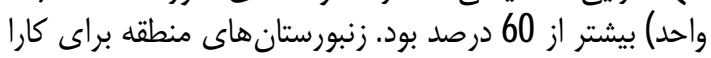

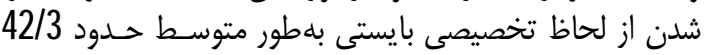

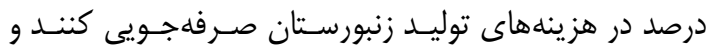


جدول1 - توزيع فراوانى كارايى فنى، اقتصادى و تخصيصى زنبورستانهاى شهرستان خرمآباد Table 1. Distribution of technical, economic and allocative efficiency of apiaries in Khorramabad city

\begin{tabular}{|c|c|c|c|c|c|c|c|c|c|}
\hline \multicolumn{3}{|c|}{ كارايى تخصيصى } & \multicolumn{3}{|c|}{ كارايى اقتصادى } & \multicolumn{3}{|c|}{ كارايى فنى } & \multirow[b]{2}{*}{ (درصح كاريى } \\
\hline (درماوعى & (دربلى) & فراوانى مطلق & فراورانى & (دروضبى) & فراوانى مطلق & (در فرعى & (دروربى) & فرالقى & \\
\hline $12 / \mathrm{C}$ & $12 / \mathrm{C}$ & 15 & $14 / 6$ & $14 / 6$ & 17 & $1 C / \Xi$ & $1 C / \Xi$ & 12 & كمتر از CC \\
\hline 31 & $1 \varepsilon / 1$ & 27 & $34 / 4$ & $1 \mathcal{C} / \mathcal{E}$ & 2 & $24 / \mathrm{C}$ & $14 / 6$ & 17 & $5 C<4 C$ \\
\hline 56 & 2 & $x$ & $5 / / 7$ & $2 E / \Xi$ & 27 & $4 E$ & $1 \varepsilon / 1$ & 27 & $6 C \mathrm{C} C \mathrm{C}$ \\
\hline$\pi / \epsilon$ & $14 / 6$ & 17 & $74 / 1$ & $16 / 4$ & 1 & 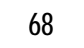 & 25 & $x$ & 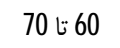 \\
\hline $84 / 4$ & $1 \equiv / \varepsilon$ & $1 \epsilon$ & 81 & $12 / \mathrm{C}$ & 15 & $85 / 4$ & $16 / 4$ & 1 & 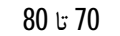 \\
\hline $9 E / 1$ & $\varepsilon / 7$ & $1 C$ & $94 / 7$ & $7 / 7$ & $\subseteq$ & $94 / 7$ & 1C/E & 12 & X \\
\hline $10 C$ & $\epsilon / \mathrm{C}$ & $\varepsilon$ & $1 \propto$ & 5に & $\epsilon$ & 100 & $5 / \equiv$ & $\epsilon$ & 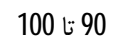 \\
\hline
\end{tabular}

جدول2 - نتايج كارايى فنى، اقتصادى و تخصيصى زنبورستانهاى شهرستان خرمآباد Table 2. Results of technical, economical and allocative performance of apiaries in Khorramabad city

\begin{tabular}{|c|c|c|c|c|}
\hline انحر اف معيار & حداكثر حلر & حداقل & ميانكَين & كارايى \\
\hline $4 / 7]$ & $10 C$ & E/4 & $6 / 1$ & كارايى فنى \\
\hline $6 / 47$ & $1 \propto$ & $15 / 4$ & $54 / 6$ & كارايي اقتصادى \\
\hline $5 / 91$ & 10 & $1 \mathrm{C} / 1$ & $5 / / 7$ & كارايى تخصيصى \\
\hline
\end{tabular}

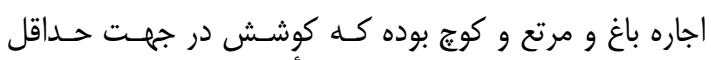

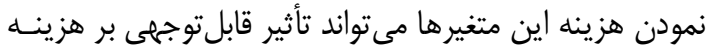
كل اين واحدها داشته باشد مند

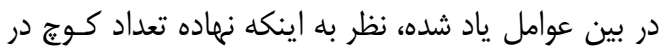

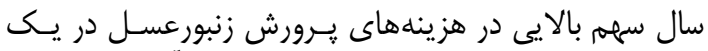

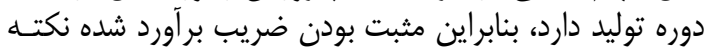

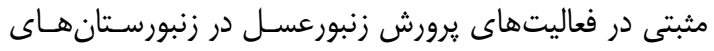

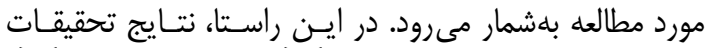

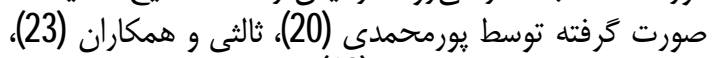

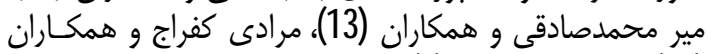

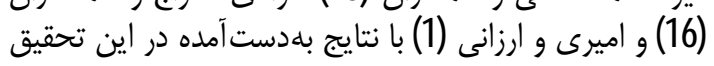

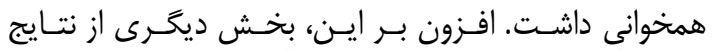

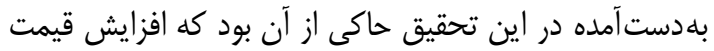

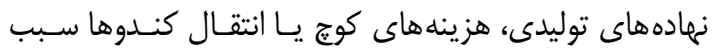

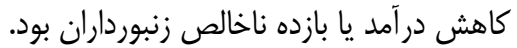

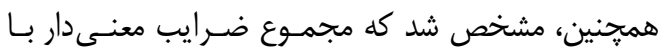

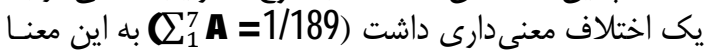

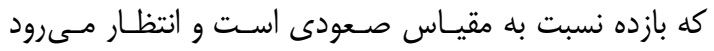

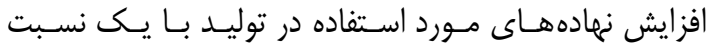

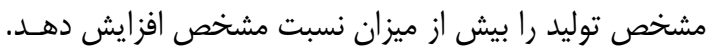

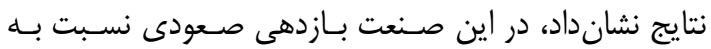

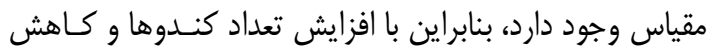

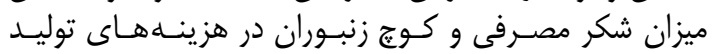
صرفه جويى مئ شود.

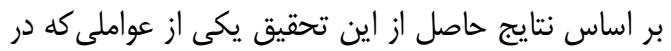

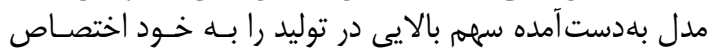

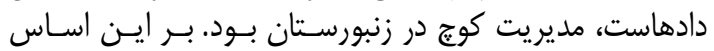

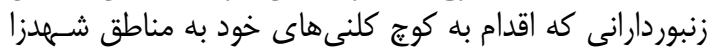

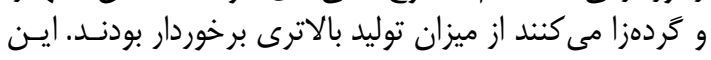

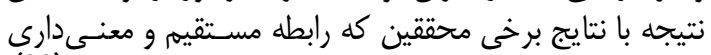

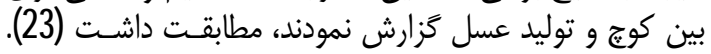

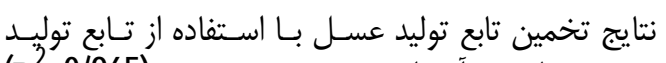

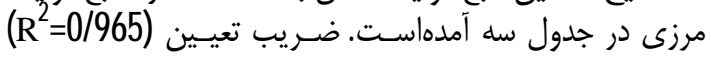

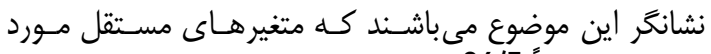

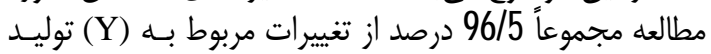

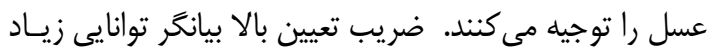

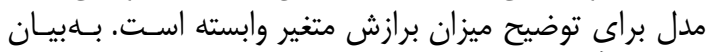

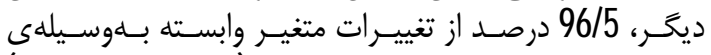

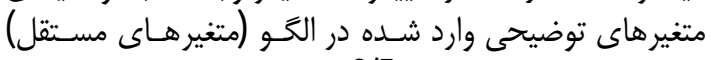

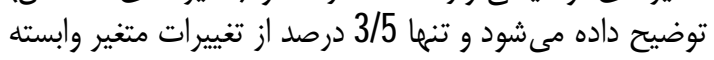

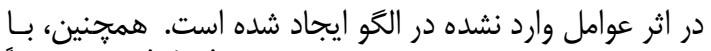

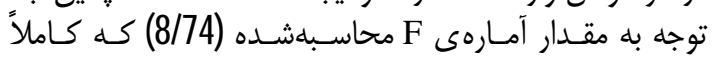

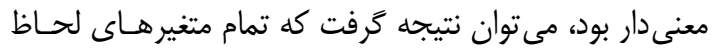

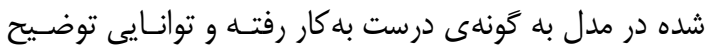
متغير وابسته را داشتند.

ضريب عرض از مبدأ (5/19) داراى اهميت آمـارى بــالا

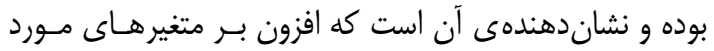

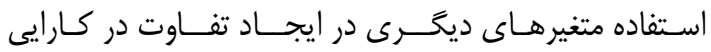

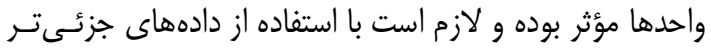
در اين خـصوص اقــدام شود.

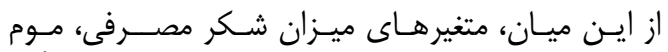

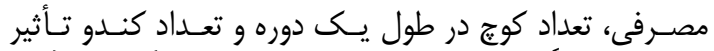

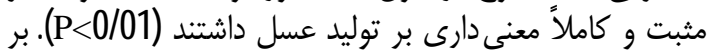

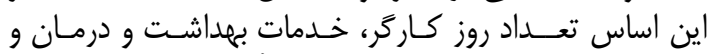

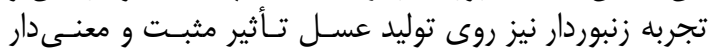

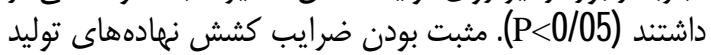

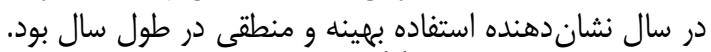

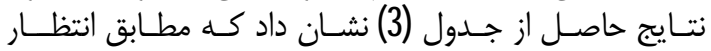

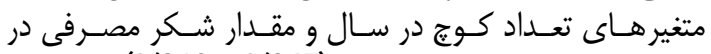

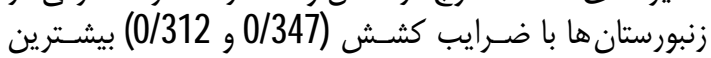

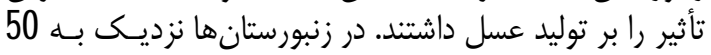

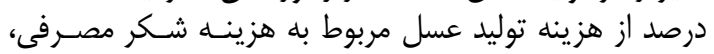


درمان نشان از استفاده بيشتر از حد معمول از اين نهاده اسـت

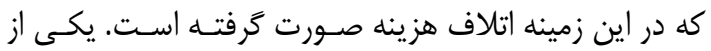

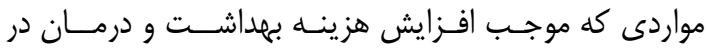

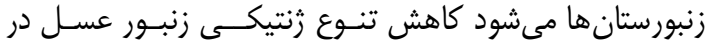

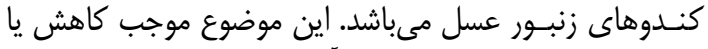

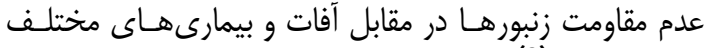

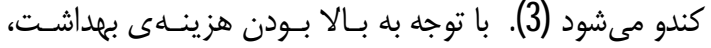

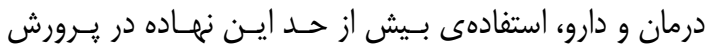

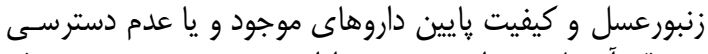

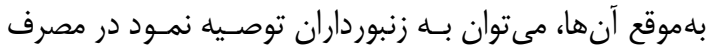

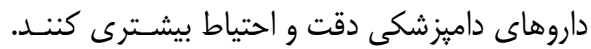

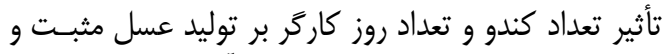

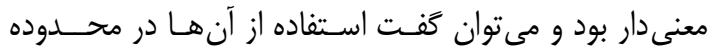

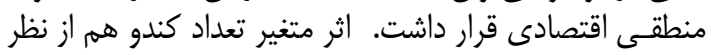

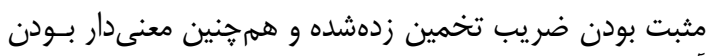

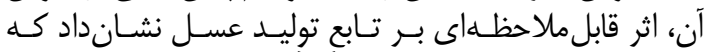

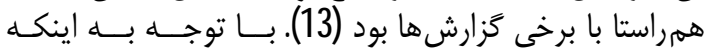

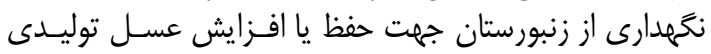

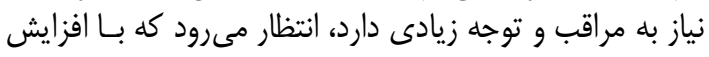

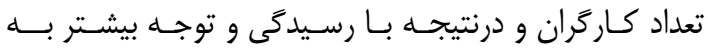

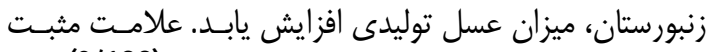

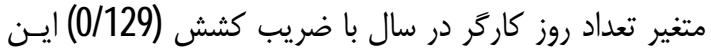

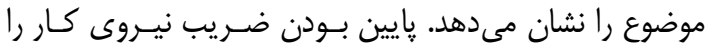

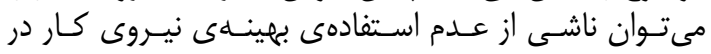

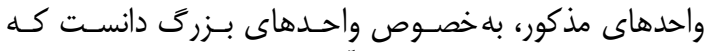

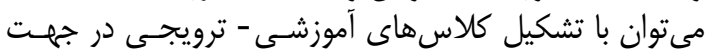

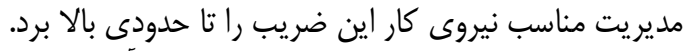

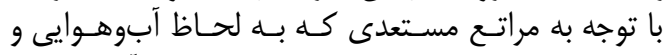

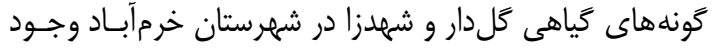

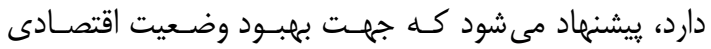

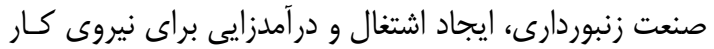

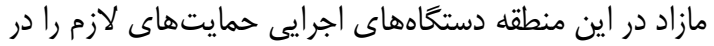

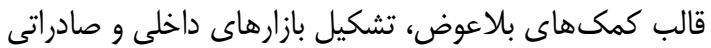

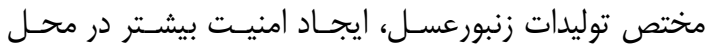

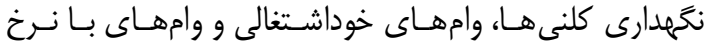

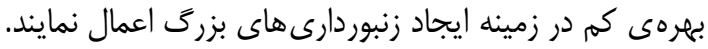

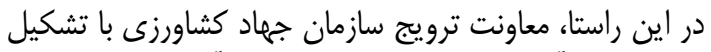

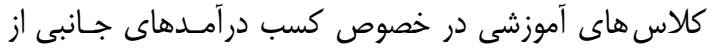

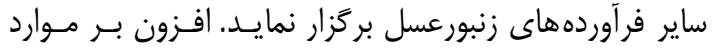

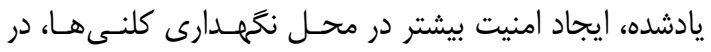

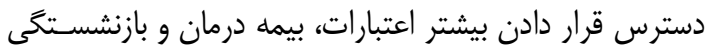
زنبورداران توصيه مىشود.
در ميان نهادهاى توليد، ميزان شكر مصرفى، تعـداد كـوج در

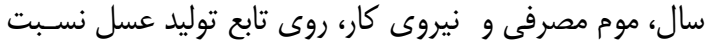

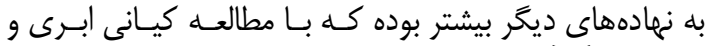

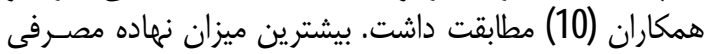

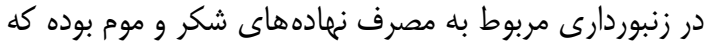

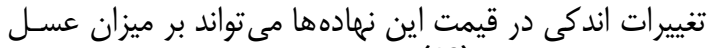

توليدى اثر كذار باشد (19).

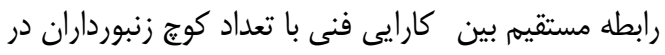

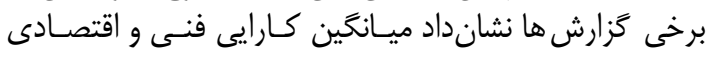

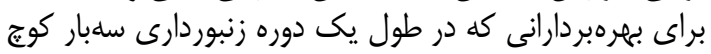

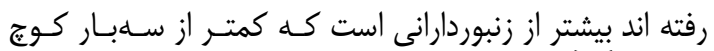

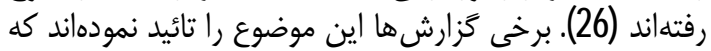

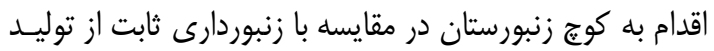

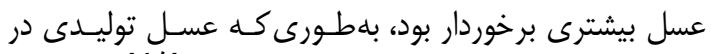

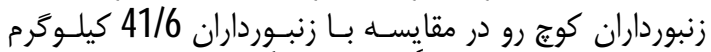

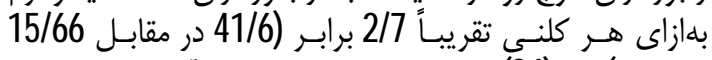

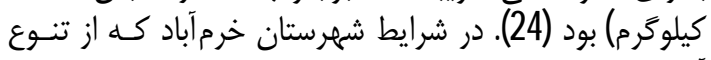

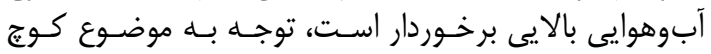

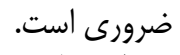

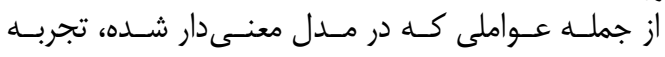

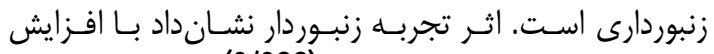

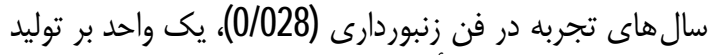

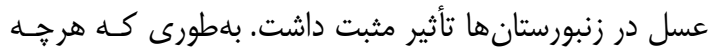

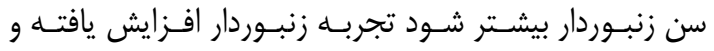

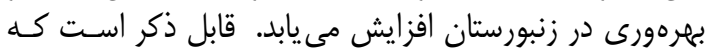

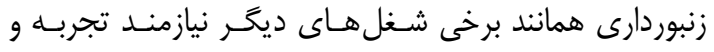

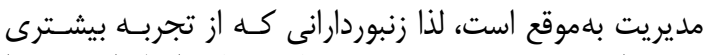

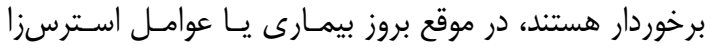

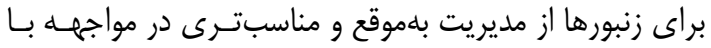

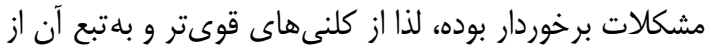

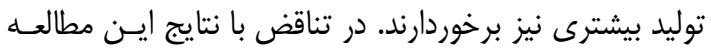

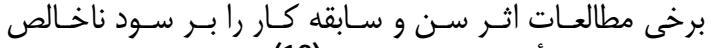

زنبوردارى بى تأثير گَزارش نمودند (13).

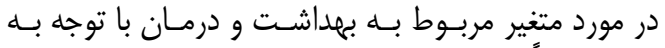

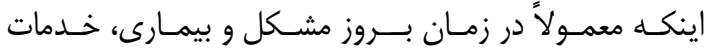

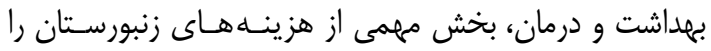

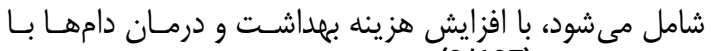

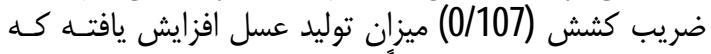

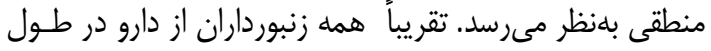

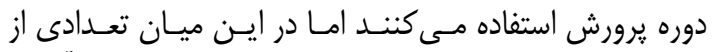

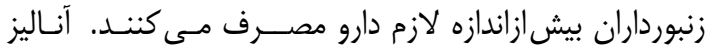

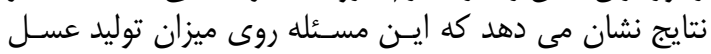

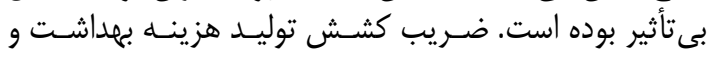


جدول3 - نتايج تخمين تابع توليد مرزى عسل در زنبورستانهاى شهرستان خرمآباد Table 3. Estimates of Frontier production function of honey in the apiaries of Khorramabad city

\begin{tabular}{|c|c|c|c|c|}
\hline سطح معنى دارى & مقدار t & خطاى معيار تخمين SE & مقدار ضريب & متغيرهاى مستقل \\
\hline (/) $]$ & $5 / 32$ & प/O5 & (/3) & ميززان كـل شكر مصـرفى X1 \\
\hline$\alpha 032$ & $2 / 69$ & Q012 & $0129^{*}$ & 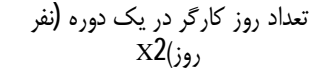 \\
\hline q016 & $3 / 01$ & Q011 & Q107" & خدمات واكسن، دامِيزشَّ، بهداشت و \\
\hline$c / 01$ & $4 / 6$ & $C / Q^{E}$ & (/OA) & تعداد كندو X4 \\
\hline C/OOE & $\equiv / \mathbb{C}$ & C/OIC & (/34) & Xع \\
\hline C/OOK & $5 / 15$ & C/06: & (/27 & موم مصرفي XE \\
\hline C/ORE & $2 / 97$ & C/OOK & $C / O R E$ & تجربه زنبورداري X7 \\
\hline C/O0] & $\varepsilon / 17$ & C/4] & $5 /]^{\circ}$ & عرض از مبداً \\
\hline (/00] & - & . & $\varepsilon / 74$ & F محاسهششه F \\
\hline- & - & - & (/965 & ضريب R \\
\hline
\end{tabular}

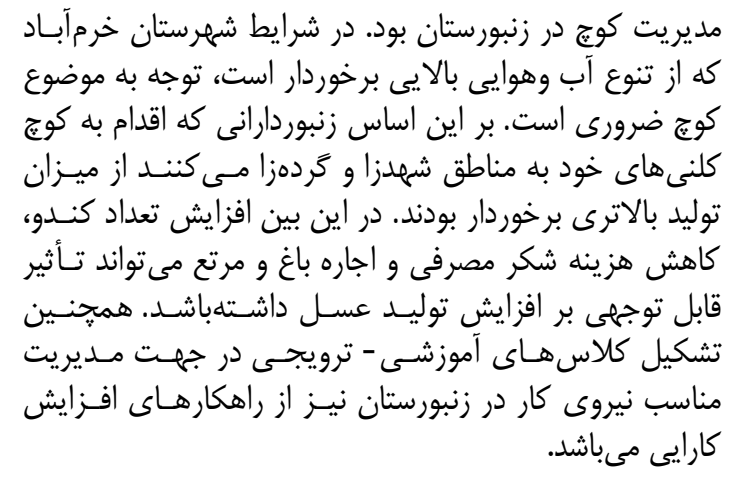

مديريت كوج در زنبورستان بود. در شرايط شهرستان خرمآبـاد

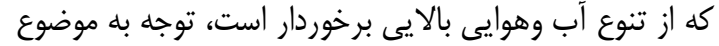

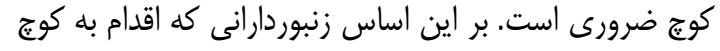

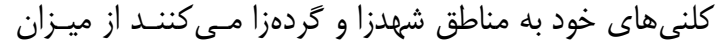

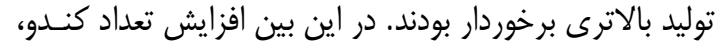

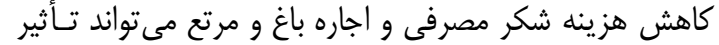

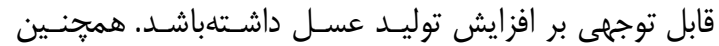

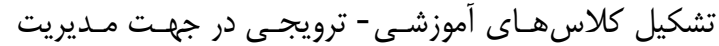

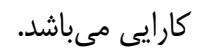

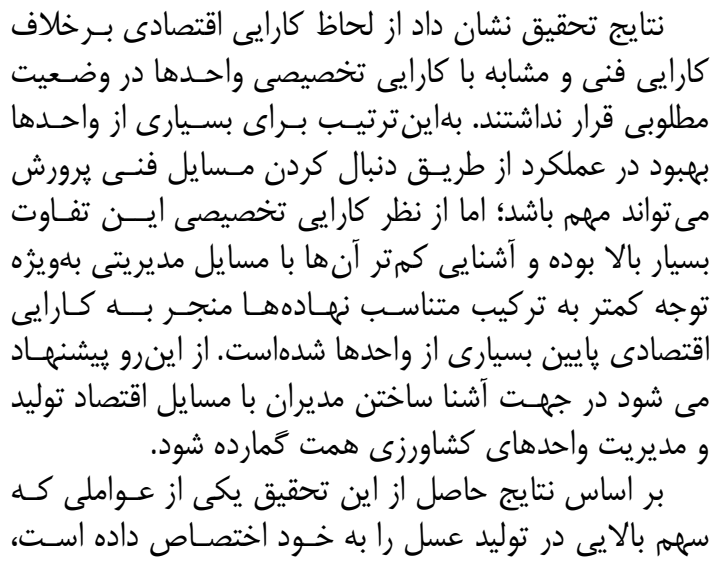

1. Amiri, F and H Arzani. 2011. Setting priorities right places beekeepers using AHP, Iranian Journa of Range and Desert Research, 19(1): 159-177 (In Persian).

2. Anonymous. 2018. Performance report of the Deputy of Improvement of Livestock Production in Lorestan Province in 2018. Agriculture jihad organization of Lorestan (In Persian).

3. Bahador, Y., M. Mohammadabadi, A. Khezri, M. Asadi and L. Medhati. 2016. Study of Genetic Diversity in Honey Bee Populations in Kerman Province using ISSR Markers. Research on Animal Production, 7(13): 192-186 (In Persian).

4. Cochran, W. 1977. Sampling techniques. 3rd Edition, Wiley publishers, New York.

5. Farrel, M.J. 1957. Measurement of productive efficiency. Journal of the Royal Statistical Society. Series A. General, 120, part 3: 253-81.

6. Ghaderzadeh, H., F. Kanaani and A. Vaziri. 2013. Productivity measurement inputs honey production in Kurdistan Province (Case study: Beekeepers of Sanandaj city), Proceedings of the Sixth conference on agricultural research findings, Sanandaj, Kurdistan University (In Persian).

7. Greene, W.H. 1980. Maximum likelihood estimation of econometric frontier functions. Journal of Econometrics, 13: 27-56.

8. Gujarati, D.N. 2003. Basic Econometrics. 4th ed., McGraw-Hill Higher Education, 217-222.

9. Gürer, B. and E. Akyol. 2018. An empirical analysis of technical efficiency determinants in beekeeping farms: evidence and policy implications from Niğde Province, Turkey. Journal of Agriculture and Environment for International Development-JAEID, 112(2): 343-359.

10. Kiani abri, M., R. Khosh akhlaqh and A. Nilfrooshan. 2000. Analysis of technical efficiency, locative and economic beekeepers in Isfahan provinc. Agricultural Economics and Development, 8(32): 261272 (In Persian).

11. Kompas, T. and T.N. Che. 2004. Production and technical efficiency on Australian dairy farms. International and Development Economics, 4: 57-77.

12. Meeusen, W. and J. Van Den Broeck. 1977. Efficiency estimation form Cobb Douglas production function with composed error. International Economic Review, 18: 435-444. 
13. Mirmohammad Sadeqi, J., M. Edris and M. Mostajeran. 2007. Factors affecting the incomes of beekeepers city of Isfahan, Najaf Abad and the city of Khomeini, Journal of Development and Productivity, 2(6): 1-12 (In Persian).

14. Mohammadi, P., J. Nazemi Rafie and J. Rostamzadeh. 2018. Evaluation of Phylogenetic Characteristics of Iranian Honeybee (Apis mellifera meda) Populations based on Mitochondrial ND Gene. Research on Animal Production, 9(21): 93-104 (In Persian).

15. Mojaverian, M. and H. Salari Bana. 2014. Study of Relationship between Production Efficiency (by Variable Returns) and Beekeeping Unit Size in Mazanderan Province. Agricultural Economic and Development, 21(83): 19-34 (In Persian).

16. Moradi Kafraj, M., D. Mohammadi and A. Moradian. 2009. Educational needs of beekeepers province in the marketing field. Iranian Journal of Agricultural Economics and Development, 43(2): 18-27 (In Persian).

17. Nemati, S.A., G.H. Tahmasbi and M. Noori. 2015. Relative contribution of different managing factors on production of honeybee colonies in Alborz province. Animal Production Research, 39(4): 89-98 (In Persian).

18. Onwumere, J., F. Onwukwe and C.S. Alamba. 2012. Comparative Analyses of Modern and Traditional Bee Keeping Entrepreneurships in Abia State, Nigeria. Journal of Economics and Sustainable Development, 3(13): 1-9.

19. Parhizkari A., M.M. Mozafari, M. Mahmoudi and M. Showkat Fadaei. 2014. A survey on the economic situation of beekeeping industry in susitable rangelands to honey bee breeding (Case study: Alamout rangelands). Journal of Range Management, 1(3): 113-132 (In Persian),

20. Pour mohammadi, H. 1996. Economic Survey of the honey bee industry. MSc Thesis joined Islamic Sciences and Economics, University of Imam Sadiq, $127 \mathrm{pp}$ (In Persian).

21. Richmond, J. 1974. Estimating the efficiency of production. International Economic Review, 15: 515521.

22. Roberts, M.C., B.K. Goodwin and K. Coble. 1998. Measurement of price risk in revenue insurance: Implication of distributional assumption. Paper presented at the AAEA summer meeting in Salt Lake City.

23. Salesi, M., A. Nilforooshan, M. Kiani and A. Abbasian. 2003. Economic estimates beekeeping jobs to cover the costs (salaries) a family. Proceedings of the Fifth Seminar beekeeping, Animal Science Research Institute, Ministry of Agriculture jihad, 71-72 (In Persian).

24. Sharma, R. and R. Bhatia. 2001. Economics of stationary and migratory Beekeeping in Himachal Pradesh. Agricultural Science Digest, 21(3): 196-197.

25. Shiferaw, K. and D. Gebremedhin. 2016. Technical efficiency of small-scale honey producers in Ethiopia: A stochastic frontier analysis. EconPapers, https://EconPapers.repec.org/RePEc:pra:mprapa: 69332.

26. Solghi, M. 2010. Efficiency analysis of beekeepers in Hamedan province. Proceedings of the seventh iranian bee research seminar, Animal Science Research Institute, 139-140 (In Persian).

27. Timmer, C.P. 1971. Using a probabilistic frontier production function to measure technical efficiency. Journal of Political Economy, 79(4): 776-794.

28. Turvey, C.G. and J. Zaho. 1999. Parametric and nonparametric crop yield distribution and their effects on all risk crop insurance premium. Department of Agricultural Economics and Business, University of Guelph, Ontario, Canada.

29. Zibaie, M. and M. Mahmoudzadeh. 2010. Analysis of total factor productivity fish farm units in Fars province: application of Data Envelopment Analysis (DEA). Agricultural Economics and Development, 72: 43-73 (In Persian). 


\title{
Efficiency Determination of Apiculture Units Using a Stochastic Frontier Analysis (SFA) Method in Lorestan Province (Case Study of Khorramabad City)
}

Behrouz Yarahmadi ${ }^{1}$, Mohsen Mohammadi Saei ${ }^{2}$, Karim Ghorbani ${ }^{3}$ and Reza Pahlavi ${ }^{4}$

1 - Assistant Professor, Faculty of Animal Science Research, Agricultural and Natural Resources Research Center of Lorestan, Agricultural Research, Training and Promotion Organization (Corresponding author: Behrouzy@gmail.com)

2 and 3- Ph.D Graduated and Research lecturer. in Animal Sciences, Department of Animal Science Research, Agricultural and Natural Resources Research Center of Lorestan, Agricultural Research, Training and Promotion Organization.

4- Doctor of Agricultural Economics, Lorestan Agricultural and Natural Resources Training and Research Center, Agricultural Research, Education and Promotion Organization Received: April 15, $2019 \quad$ Accepted: October 28, 2019

\begin{abstract}
This study was conducted to evaluate the production conditions of beekeeping units and determine the efficiency of the units, estimating the Stochastic Frontier Analysis (SFA) of the apiaries in Khorramabad city and evaluating the management and honey production function of these units. This study was carried out in 116 farmsteads in Khorramabad city during 2017. The data collection method was face to face interviews and questionnaires. Data on production functions were estimated by Cobb Douglas functions and technical efficiency by Stochastic Frontier Analysis (SFA) method. The results showed that per capita honey production per hive in Khorramabad city was $8.23 \mathrm{~kg}$. In terms of the cost of inputs were in beekeeping, the cost of renting a garden and ranch $16.28 \%$, the work and keeping of bees $15.05 \%$, of sugar $24.92 \%$, the migration $22.07 \%$, the cost of buying wax $17.52 \%$, the cost of medicine and treatment $1.19 \%$ and miscellaneous expenses $2.97 \%$, respectively. The average technical, allocative and economic efficiency was $62.1,57.7$ and $54.6 \%$, respectively, that indicating significant potential of the units in increasing their efficiencies. The results of honey production function showed that the number of migrations per year and the amount of consuming sugar in the apiaries with the coefficients $(0.347$ and 0.322$)$ had the highest effect on honey production $(\mathrm{P}<0.01)$. The results showed that most apiaries in Khorramabad city due to lack of observance of economic principles in management, lack of knowledge of the factors affecting the production had low efficiency. Among beneficiaries of the three technical efficiency, allocative and economic efficiency were for economic efficiency major difference. Generally, in order to develop the beekeeping industry in further, the implementation of the honey guaranteed rate, the relative stability of sugar price, the creation of more security at the colony's premises, the availability of more bank credits, the formation of beekeepers guild, the creation of domestic markets and exports for beekeepers and production insurance is needed.
\end{abstract}

Keyword: Apiaries, Cobb Douglas Functions, Stochastic Frontier Analysis (Sfa), Efficiency, Khorramabad City 